\title{
Self-Management Education for the Quality of Life of Patients with Pulmonary Tuberculosis
}

\author{
Eppy Setiyowati $^{1}$, Umi Hanik ${ }^{2}$, Ni \\ Njoman Juliasih ${ }^{3}$, Achmad Wahdi ${ }^{4}$ \\ ${ }^{1,2}$ Faculty of Nursing and \\ Midwifery, Nahdlatul Ulama \\ University of Surabaya \\ ${ }^{3}$ Institude of Tropical Diseases, \\ Airlangga University \\ ${ }^{4}$ Magister Program Study Of \\ Applied Nursing, University of \\ Nahdlatul Ulama Surabaya, \\ Indonesia \\ Email: \\ eppy@unusa.ac.id
}

Received: October 5, 2020

Accepted : November 11, 2020

Published : November 30, 2020

\begin{abstract}
Introduction: Treatment for pulmonary tuberculosis (TB) may become a problem when the patients show no adherence to the treatment and feel bored with its long duration. This condition may lead to the drop out in the treatment. Therefore, this study aimed at analyzing the effects of self-management education on the quality of life of patients with pulmonary TB. Method: The design of this study is quasi-experiment conducted in 3 Puskesmas (Community Health Center), in which 150 respondents was divided into 2 groups: 75 respondents in the control group and 75 respondents in the treatment group. They were chosen as the samples by using simple random sampling technique. The data were collected by conducting pretest to measure the quality of life, doing intervention through selfmanagement education, and finally providing posttest. Furthermore, the data were analyzed by using Mann Whitney U test and Wilcoxon signed rank test.Result: Change in perceptions that this disease is infected by Mycobacterium tuberculosis, the right place for the treatment is Puskesmas or hospitals, and a high hope for the cure needs supports form the family and medical workers Conclusion, self-management education increases the quality of life of the patients with pulmonary TB. The future research is expected to analyze their life expectancy more deeply.
\end{abstract}

Keywords: Quality of life, pulmonary TB, Mycobacterium, Health service, life expectancy

Copyright (C) 2020 IIK STRADA Indonesia All right reserved.

This is an open-acces article distributed under the terms of the Creative Commons Attribution-ShareAlike 4.0 International License.

\section{INTRODUCTION}

Tuberculosis (TB) is an infectious disease a global problem, mostly found in developing countries (Ambaw et al., 2018); (Chang et al., 2004); (Guo et al., 2009a); (Medicine et al., 2016). TB problem is exacerbated by the presence of cormobidities, which causes inhibiting factors in the treatment in the period treatment (Magharei et al., 2019);(Medicine et al., 2016);(Shahhamzeh et al., 2017).

TB control in Indonesia through the national TB program has long been carried out in line with the implementation of short-term treatment strategies and direct monitoring (Directly Oberserved Treatment Short-course, DOT) carried out in puskesmas (health primary) stage (Sule et al., 2014); (Yu et al., 2014); (Sharma et al., 2013). 
The elimination tuberculosis is also one of the 3 main focuses of the government in addition health sector to reducing stunting and increasing the coverage and quality of immunizations (Muhammad et al., 2014); (Yu et al., 2014); (Magharei et al., 2019). The vision relation build to this disease world is free tuberculosis, zero deaths, illnesses, and suffering caused by tuberculosis (Navicharern, 2012); (Sule et al., 2014); (Xu et al., 2018).

The world hopes is free of tuberculosis, so the quality of life in TB sufferers needs to be investigated so that the treatment process can be run optimally and continuously (Fryer et al., 2013); (Iti et al., 2019); (Ambaw et al., 2018); (Estuningsih et al., 2019). Quality of life as an individual's perception is related to their goals, hopes, standards and concerns (Iti et al., 2019); (Magharei et al., 2019); (Chang et al., 2004); (Li et al., 2017); (Grady \& Gough, 2018).

Factors affecting Quality of life are physical health, psychological conditions, personal beliefs, social relationships and their relationship with important factors in their environment (Of et al., 2019); (Iti et al., 2019); (Ambaw et al., 2018); (Grady \& Gough, 2018). Patients TB with drug resistant have different quality of life compared to Non-drug resistant TB patients, Non drug resistant TB patients have a better quality of life than TB resistant drug patients (Shahhamzeh et al., 2017); (Guo et al., 2009a); (Tung et al., 2013). The difference in quality of life is the general quality of life (global quality of life), global health, psychological health, and environmental quality of life (Guo et al., 2009a); (Sule et al., 2014); (Nahid et al., 2019). Aspects of physical health and social relationships do not any difference between TB drug resistant patients with patients who are Non multiple drug resistant TB (Mousa et al., 2018); (Malik et al., 2018); (Sule et al., 2014); (Sangprasert et al., 2019).

Self management education in pulmonary TB patients is 3 steps, process creation, peer gorup discusion, transfer and sharing process (Estuningsih et al., 2019); (Grady \& Gough, 2018); (Tung et al., 2013);(Guo et al., 2009a).

The purpose of the study was affect self management education to quality of life in patients with pulmonary TB.

\section{METHOD}

Quasi-experimental research design with one group intervention approach and one group control design. The population in 3 puskesmas at Surabaya City, sample size 150 respondents was divided into 2 groups: 75 respondents in the control group and 75 respondents in the treatment group.

Treatment given by researchers is family empowerment including counseling, guidance / counseling and demonstrations related to TB, how to care, how to prevent transmission and treatment of pulmonary TB involving patients and families for +1 hour each meeting as many as 6 meetings for 6 weeks, according to agreement with respondent. Supporting instruments in the research were booklets, flip sheets and demonstration materials for pulmonary TB independent care (Jaber et al., 2016); (Sun et al., 2018); (Bischoff et al., 2012).

Questionnaire data collection measures the quality of life and the process intervention carried out by participant observation. WHOQOL-BREF consists of two parts namely overall quality of life and general health containing 24 questions WHOQOL-100 (Bauer et al., 2015); (Salehitali et al., 2019); (Sule et al., 2014); (2).

World Health Organization (WHO) develop instruments measuring quality of life are WHO Quality of Life-BREF (WHOQOLBREF) (Chang et al., 2004); (Guo et al., 2009a); (Jaber et al., 2019). WHOQOL-BREF consists of four domains namely physical, psychological, social and environmental. The questionnaire was given during the pre-test and post-test. The research process was carried out for 1 month, divided into 2 weeks for the control group and 2 weeks for the treatment group. Analyzed using statistical Wilcoxon signed rank test, level of significance $\alpha=0,05$. That means, if $(p)=0,05$, then $\mathrm{H} 1$ received, this means there is influence self management education toward Quality of Life (QoL) pulmonary TB sufferers. Different test control group and treatment were Mann Whitney $\mathrm{U}$, test level $\alpha=0,05$

\section{RESULT}

Respondent demographic data are the characteristics of respondents which include 1) gender, 2) age, 3) occupation, 4) education, 5) duration of treatment of pulmonary tuberculosis, the results obtained in table 1. Quantitative research results (with the Wilcoxon signed rank test test and the Mann Whitney U Test) obtained the results in the table 2. Statistical test results using Wilcoxon 
signed rank test, treatment group (groups that receive self management education treatment ) were $p$ $=0,003$ on the physical health domain means $p=0,05$, then the hypothesis is accepted meaning there is a significant effect of self-management education on improving the quality of life (physical health domain) in patients with pulmonary TB. Statistical test result using Wilcoxon Signed Rank test, in the control group (groups that don't get self management education ) were $p=0,317$ in the physical health domain which means there is no difference in quality of life (physical health domain) in patients with pulmonary TB between pretest and posttest. Difference in average quality of life (physical health domain) at the pretest in the treatment group and the control group using Mann Whitney $U$ Test were obtained $p=0,167$, this shows that there is no average difference between the control group and the treatment group. Difference in mean quality of life (physical health domain) at posttest in the treatment group and the control group using Mann Whitney U Test were obtained $p=$ 0,000 , this shows that there are differences in the mean improvement in quality of life (domain Physical health) between the treatment group (the group that got SME) and the control group (the group that did not get

SME).

The psychological domain, statistical test results using Wilcoxon Signed Rank test, in the treatment group were $p=0,003$ means it $p=0,05$ then the hypothesis is accepted meaning there is a significant effect of self management education on improving the quality of life (psychological domain) in patients with pulmonary TB. The value control group $p=0,317$ means it $p=0,05$ then the hypothesis is rejected meaning that there is no improvement in the quality of life (psychological domain) in patients with pulmonary TB. Difference in average quality of life (psychological domain) at pretest in the treatment group and the control group using Mann Whitney $U$ test were obtained $p=$ 0,167 , this shows that there is no average difference between the control group and the treatment group. Difference in average quality of life (psychological domain) at posttest in the treatment group and the control group using Mann Whitney U Test were obtained $p=0,000$, this shows that there are differences in the mean improvement in quality of life (psychological domain) between the treatment group (the group that gets SME) and the control group (the group that does not get SME).

The social domain, statistical test results use Wilcoxon signed rank test, the treatment group $p=$ 0,046 means it $p=0,05$ then the hypothesis is accepted meaning that there is a significant effect of Self management education on improving the quality of life (social domain) in patients with pulmonary TB. The social domain using Wilcoxon signed rank test, in the control group were $p=$ 0,157 means there is no difference in quality of life (social domain) in patients with pulmonary tuberculosis. Difference in average quality of life (social domain) at the pretest in the treatment group and the control group using Mann Whitney $U$ test were obtained $p=0,061$, this shows that there is no average difference between the control group and the treatment group. Difference in average quality of life (social domain) at posttest in the treatment group and the control group using Mann Whitney $U$ test were obtained $p=0,015$, this shows that there are differences in the mean improvement in quality of life (social domain) between the treatment group (the group that gets SME) and the group control (groups that did not get SME).

The environmental domain, statistical test results use Wilcoxon signed rank test, in the treatment group is $p=1,000$ means it $p=0,05$, the hypothesis is rejected meaning that there is no significant effect of self management education (SME) on improving quality of life (environmental domain) in patients with pulmonary tuberculosis. Statistical test results using Wilcoxon signed rank test, in the control group is $p=0,564$ meaning that there is no significant difference in quality of life (environmental domain) between pretest and posttest in patients with pulmonary tuberculosis. Differences in the average quality of life (environmental domain) during the pre-test in the treatment group and the control group using the test Mann Whitney $U$ test didapatkan $p=0,101$, this shows that there is no average difference between the control group and the treatment group. The average difference in quality of life (physical health domain) at the posttest in the treatment group and the control group using Mann Whitney U Test were obtained $p=0,167$, this shows that there is no difference in the average improvement in quality of life (environmental domain) between the treatment group (the group that gets SME) and the control group (the group that does not get SME). 
Table 1 Table Distribution Responden on Caracteristic Demografic

\begin{tabular}{|c|c|c|c|c|}
\hline $\begin{array}{l}\text { Respondent } \\
\text { Demografic }\end{array}$ & $\begin{array}{c}\mathbf{F} \\
\text { (Control group ) }\end{array}$ & $\begin{array}{c}\% \\
\text { (Control } \\
\text { group) }\end{array}$ & $\begin{array}{c}F \\
\text { (Treatment } \\
\text { group) }\end{array}$ & $\begin{array}{c}\% \\
\text { (Treatment } \\
\text { group) }\end{array}$ \\
\hline \multicolumn{5}{|l|}{ Gender: } \\
\hline Male & 22 & $29,3 \%$ & 22 & $29,3 \%$ \\
\hline Famale & 53 & $70,7 \%$ & 53 & $70,7 \%$ \\
\hline Total Respondent & 75 & $100 \%$ & 75 & $100 \%$ \\
\hline \multicolumn{5}{|l|}{ Age: } \\
\hline$>25-\leq 35$ & 15 & $20 \%$ & 17 & $22,6 \%$ \\
\hline$>35-\leq 45$ & 24 & $32 \%$ & 32 & $42,7 \%$ \\
\hline$>45-\leq 60$ & 36 & $48 \%$ & 26 & $34,7 \%$ \\
\hline Total Respondent & 75 & $100 \%$ & 75 & $100 \%$ \\
\hline \multicolumn{5}{|l|}{ Profession: } \\
\hline Housewife & 11 & $14,7 \%$ & 15 & $20 \%$ \\
\hline $\begin{array}{l}\text { Private sector / } \\
\text { Employee }\end{array}$ & 28 & $73,3 \%$ & 23 & $30,7 \%$ \\
\hline Entrepreneur & 12 & $16 \%$ & 17 & $22,7 \%$ \\
\hline Driver & 27 & $36 \%$ & 10 & $13,3 \%$ \\
\hline Does not work & 3 & $5 \%$ & 10 & $13,3 \%$ \\
\hline Total Respondent & 75 & $100 \%$ & 75 & $100 \%$ \\
\hline \multicolumn{5}{|l|}{ Education level: } \\
\hline no school & 11 & $14,7 \%$ & 12 & $16 \%$ \\
\hline elementary school & 15 & $20 \%$ & 17 & $22,7 \%$ \\
\hline Junior high school & 23 & $30,7 \%$ & 27 & $36 \%$ \\
\hline Senior High School & 19 & $25,3 \%$ & 18 & $24 \%$ \\
\hline College & 7 & $7,3 \%$ & 0 & 0 \\
\hline Total respondent & 75 & $100 \%$ & 75 & $100 \%$ \\
\hline \multicolumn{5}{|l|}{$\begin{array}{l}\text { Duration of } \\
\text { treatment: }\end{array}$} \\
\hline 1-2 months & 13 & $17,3 \%$ & 34 & $45,3 \%$ \\
\hline 2-3 months & 37 & $49,3 \%$ & 17 & $22,7 \%$ \\
\hline 3-4 months & 25 & $33,3 \%$ & 24 & $32 \%$ \\
\hline Total Respondent & 75 & $100 \%$ & 75 & $100 \%$ \\
\hline
\end{tabular}

Table 2 Distribution quality of Life (Phsycal Health Domain)

\begin{tabular}{|c|c|c|c|c|c|c|c|c|}
\hline \multirow{3}{*}{$\begin{array}{l}\text { Phsycal Health } \\
\text { Domain }\end{array}$} & \multicolumn{4}{|c|}{ Treatment Group } & \multicolumn{4}{|c|}{ Control group } \\
\hline & \multicolumn{2}{|c|}{ Pre test } & \multicolumn{2}{|c|}{ Post Test } & \multicolumn{2}{|c|}{ Pre test } & \multicolumn{2}{|c|}{ Post Test } \\
\hline & f & $\%$ & $\mathbf{f}$ & $\%$ & $\mathbf{f}$ & $\%$ & f & $\%$ \\
\hline Had sufficient & 15 & 20 & 10 & 13,3 & 18 & 24 & 17 & 22,7 \\
\hline Sufficient & 18 & 24 & 12 & 16 & 35 & 46,7 & 32 & 42,7 \\
\hline good & 23 & 30,7 & 29 & 38,7 & 15 & 15 & 19 & 25,3 \\
\hline very good & 19 & 25,3 & 24 & 32 & 7 & 9,3 & 7 & 9,3 \\
\hline Total & 75 & 100 & 75 & 100 & 75 & 100 & 75 & 100 \\
\hline $\begin{array}{l}\text { Wilcoxon Signed } \\
\text { Rank Test }\end{array}$ & & $P=$ & 003 & & & & & \\
\hline Mann-Whitney & & & & Pretes & $=0$ & & & \\
\hline Test & & & & Postte & $=0,0$ & & & \\
\hline
\end{tabular}


Table 3 Distribution quality of Life (Psychological domain)

\begin{tabular}{lcccccccc}
\hline \multicolumn{1}{c}{$\begin{array}{c}\text { Psychological } \\
\text { Domain }\end{array}$} & \multicolumn{3}{c}{$\begin{array}{c}\text { Treatment Group } \\
\text { Pre test }\end{array}$} & $\begin{array}{c}\text { Post } \\
\text { f }\end{array}$ & \% & f & \% & \multicolumn{3}{c}{ Pontrol group } \\
& 12 & 16 & 9 & 12 & 15 & 20 & 12 & 16 \\
\hline Less stable & 27 & 36 & 15 & 20 & 27 & 36 & 27 & 36 \\
Fairly stable & 25 & 33,3 & 30 & 40 & 20 & 26,7 & 21 & 28 \\
Stable & 16 & 21,3 & 21 & 28 & 13 & 17,3 & 15 & 20 \\
Very stable & 75 & 100 & 75 & 100 & 75 & 100 & 75 & 100 \\
$\quad$ Total & & $P=0,003$ & & & $P=0,317$ &
\end{tabular}

Rank Test

Mann-Whitney Pretest $p=0,167$

Test $\quad$ Posttest $p=0,000$

Table 4 Distribution quality of Life (Social domain)

\begin{tabular}{|c|c|c|c|c|c|c|c|c|}
\hline \multirow[t]{3}{*}{ Social domain } & \multicolumn{4}{|c|}{ Treatment Group } & \multicolumn{4}{|c|}{ Control group } \\
\hline & \multicolumn{2}{|c|}{ Pre test } & \multicolumn{2}{|c|}{ Post Test } & \multicolumn{2}{|c|}{ Pre test } & \multicolumn{2}{|c|}{ Post Test } \\
\hline & f & $\%$ & f & $\%$ & f & $\%$ & $\mathbf{f}$ & $\%$ \\
\hline Not active enough & 12 & 16 & 5 & 6,6 & 23 & 30,7 & 20 & 26,7 \\
\hline Quite active & 29 & 38,7 & 20 & 26,7 & 30 & 40 & 30 & 40 \\
\hline Active & 27 & 36 & 42 & 56 & 17 & 22,7 & 20 & 26,7 \\
\hline Very active & 7 & 9,3 & 8 & 10,7 & 5 & 6,6 & 5 & 6,6 \\
\hline Total & 75 & 100 & 75 & 100 & 75 & 100 & 75 & 100 \\
\hline $\begin{array}{l}\text { Wilcoxon Signed } \\
\text { Rank Test }\end{array}$ & & & & & & & & \\
\hline Mann-Whitney & & & & Pretes & $=0,($ & & & \\
\hline Test & & & & Postte & $=0,0$ & & & \\
\hline
\end{tabular}

Table 5 Distribution quality of Life (Environment domain)

\begin{tabular}{|c|c|c|c|c|c|c|c|c|}
\hline \multirow[t]{3}{*}{ Social domain } & \multicolumn{4}{|c|}{ Treatment Group } & \multicolumn{4}{|c|}{ Control group } \\
\hline & \multicolumn{2}{|c|}{ Pre test } & \multicolumn{2}{|c|}{ Post Test } & \multicolumn{2}{|c|}{ Pre test } & \multicolumn{2}{|c|}{ Post Test } \\
\hline & f & $\%$ & $\mathbf{f}$ & $\%$ & f & $\%$ & f & $\%$ \\
\hline Inadequate & 12 & 16 & 12 & 6,6 & 17 & 22,7 & 15 & 20 \\
\hline $\begin{array}{l}\text { Enough } \\
\text { adequate }\end{array}$ & 32 & 42,7 & 30 & 36 & 39 & 52 & 43 & 56 \\
\hline Adequate & 23 & 30,7 & 25 & 42,6 & 19 & 25,3 & 18 & 24 \\
\hline Very adequate & 8 & 10,7 & 8 & 14,7 & 0 & 0 & 0 & 0 \\
\hline Total & 75 & 100 & 75 & 100 & 75 & 100 & 75 & 100 \\
\hline $\begin{array}{l}\text { Wilcoxon Signed } \\
\text { Rank Test }\end{array}$ & & $P=$ & & & & & 564 & \\
\hline Mann-Whitney & & & & Pret & $=0$ & & & \\
\hline Test & & & & Pos & $p=0$ & & & \\
\hline
\end{tabular}

\section{DISCUSSION}

The results of Table 1 show the differences in the improvement of Quality of Life on physical, psychological, and social health domains in the pretest and posttest treatment groups using Wilcoxon and the Mann Whitney test, resulting H1 accepted. psychologically, and socially for pulmonary tuberculosis sufferers at the Community Health Center in Surabaya. There is no significant difference in the environmental domain of Quality of Life in the pretest and posttest treatment groups using the Wilcoxon test and the Mann Whitney test resulting in H1 rejected, there is no effect of Self Management Education on improving Quality of Life. This shows that the intervention given by the researcher has an effect on the improvement of the Quality of Life of patients with pulmonary tuberculosis. Pulmonary tuberculosis is one of the deadliest diseases in the world caused by Mycobacterium Tuberculosis and is contagious (Jonker et al., 2009); (Voncken-Brewster et al., 2013); 
(Awan et al., 2012). The disease causes health problems in millions of people every year and ranks second to infectious diseases that cause death after the Human Immunodeficiency Virus (HIV) (Awan et al., 2012); (Bischoff et al., 2012); (Deribew et al., 2009).

Pulmonary tuberculosis is a threat to the Indonesian population. The disease is a chronic disease that can affect the quality of life of sufferers. Pulmonary tuberculosis raises serious problems in the concept of quality of life consisting of aspects of physical, psychological, social, and environmental health (Diaz et al., 2019); (Borji et al., 2017); (Donaldson et al., 2008). The impact of psychological burden on pulmonary tuberculosis patients will worsen physical health so that it will reduce the quality of life patients. The helplessness of pulmonary tuberculosis patients will lead to changes in adaptation to the psychological, social, and spiritual response so that it will affect the Quality of Life (QoL) sufferers.

This is in accordance with the quality of life measurement data conducted by researchers. In this study, out of 75 respondents in the treatment group, 10 people had sufficient physical health status, 12 people sufficient physical health status, 29 people good physical health status and 24 people very good physical health status. In the control group, 17 people had sufficient health status, 32 people sufficient health status, 19 people good health status and 7 people very good physical health status. Items on physical health in question include pain (coughing and tightness in pulmonary TB, dependence on drug ingredients and medical assistance, energy and fatigue, mobility, sleep satisfaction, ability to move, and ability to work) (Sule et al., 2014); (Muhammad et al., 2014); (Xu et al., 2018).

The psychological domain, out of 75 respondents in the treatment group, 9 people have a less stable psychological status, 15 people fairly stable psychological status, 30 people stable psychological status and 21 people have very stable psychological status. (Yu et al., 2014); (Grady \& Gough, 2018); (Magharei et al., 2019); states that self management education is a person's ability to manage strengths greater than oneself. The control group, 12 people had less stable psychological status, 27 fairly stable, 21 have stable and 15 people had very stable psychological status. Items in psychological terms include positive feelings, appreciation for life, concentration, body appearance, self-esteem, and negative feelings (Grady \& Gough, 2018); (Chang et al., 2004) .

The social domain, out of the 75 respondents in the treatment group, 5, responden less active enough, 20 responden have quite active social status, 42 responden have active status social domain and 8 respondeen have very active social status. In the control group, 20 responden have less active social status, 30 responden have quite active social status, and 5 responden have active social status. In the environmental domain, out of 75 respondents in the treatment group, 12 people have inadequate environmental status, 30 people enough adequate environmental status, 25 people adequate environmental status and 8 people with an adequate environmental domain. In the control group out of 75 respondents in the treatment group, 15 people have inadequate environmental status, 43 people enough adequate environmental status, 18 people adequate environmental status and 0 people with an adequate environmental domain

The treatment group in table 2 shows an increase in quality of life (physical health domain) in almost all respondents. While the control group did not experience a significant difference, because based on research conducted by (2); (17); (38) in the article it has been proven that self management education affects the improvement of individual health. This supports that the control group that is only given standard treatment in the form of OAT alone without accompanied by self management education measures found no significant differences in aspects of physical health.

The treatment group in table 3 shows an increase in quality of life (psychological domain), out of 75 respondents in the treatment group, 9 people less stable psychological domain status, 15 people fairly stable psychological domain status, 30 people stable psychological domain status and 21 people stable psychological domain status. In the control group out of 75 respondents, 12 people less stable psychological domain status, 27 people fairly stable psychological domain status, 21 people stable psychological domain status and 15 people stable psychological domain status. Self management education is education to manage the ability of the self effectively in improving the welfare of the respondent's life where this action will be more focused on the ability of the self to understand the illness, transmission, prevention and treatment that must be done by TB lung sufferers so that TB lung sufferers are able to accept conditions illness and illness, good conditions and acceptance will improve the quality of life (Yu et al., 2014); (Monninkhof et al., 2003). The control group did not 
experience a significant difference, because the psychological aspects of pulmonary tuberculosis patients who were not given self management education and were only given standard therapy by the puskesmas showed no significant changes. This will cause psychological resistance which will affect the low psychological well-being (Deribew et al., 2009); (22).

The treatment group in table 4 shows an improvement in the quality of life (social domain) of almost all respondents wasactive socialdomain. Social welfare is a system of life and social life, both material and spiritual, which includes a sense of safety, decency, and inner peace to carry out the fulfillment of physical, spiritual, and social needs as well as possible for themselves, families, and society by upholding the rights and human rights obligations (Guo et al., 2009b); (Sule et al., 2014). This supports that education is one of the important aspects in the realization of social welfare. Educational aspects can be built by growing 5 aspects in a person, namely knowing, understanding, understanding, analysis and synthesis. These five aspects are requirements that must be built when taking self management education actions.

The treatment group in table 5 did not show a significant improvement in quality of life (environmental domain). The environmental domain consists of financial resources, freedom, security, physical comfort, health, and social care (accessibility and quality), home environment, opportunities to obtain new information and skills, participation and opportunities for recreation, and physical environment (pollution and noise ) (Louw et al., 2016); (Jaber et al., 2019). Financial difficulties are a component that is not influenced by actions of self management education. This is based on the understanding that self management education is education given to pulmonary TB patients so that patients are able to manage their abilities (Deribew et al., 2009); (Magharei et al., 2019). The target of self management education is to increase the intensity of emotions, and to have a dramatic impact on both emotional and physical changes (Jonker et al., 2009); (Yu et al., 2014). Self management education does not include actions to overcome one's finances (Yu et al., 2014); (Deribew et al., 2009). Self management education that has been done will cause emotional strength for patients, so patients will positively receive pulmonary tuberculosis through determination, hope of recovery, and be able to make decisions. This will improve the quality of life of tuberculosis patients, with indicators of improvement in physical, social, and psychological aspects.

\section{CONCLUSIONS AND RECOMMENDATIONS}

\section{Conclusions}

1. Health education is given correctly about the independent care of patients with pulmonary tuberculosis to patients and families, patients with pulmonary $\mathrm{Tb}$ can live like other healthy people, which in turn can increase productivity and the level of welfare of the family where the patient lives.

2. Self management education can be used as an alternative method in improving the independent care of people with pulmonary TB at home.

\section{Recommendations}

1. The need for socialization about understanding $\mathrm{TB}$ and the management of good and right to patients and families through health education.

2. The need for preparation of guidelines on how to independently care for patients with pulmonary $\mathrm{Tb}$ at home

\section{REFERENCES}

Ambaw, F., Mayston, R., Hanlon, C., Medhin, G., \& Alem, A. (2018). Untreated depression and tuberculosis treatment outcomes, quality of life and disability, Ethiopia. Bulletin of the World Health Organization, 96(4), 243-255. https://doi.org/10.2471/BLT.17.192658

Awan, M. S., Waqas, M., \& Aslam, M. A. (2012). Factors influencing quality of life in patients with active tuberculosis in Pakistan. World Applied Sciences Journal, 18(3), 328-331. https://doi.org/10.5829/idosi.wasj.2012.18.03.3350

Bauer, M., Ahmed, S., Benedetti, A., Greenaway, C., Lalli, M., Leavens, A., Menzies, D., Vadeboncoeur, C., Vissandjée, B., Wynne, A., \& Schwartzman, K. (2015). Health-related quality of life and tuberculosis: A longitudinal cohort study. Health and Quality of Life Outcomes, 13(1). https://doi.org/10.1186/s12955-015-0250-4 
Bischoff, E. W. M. A., Akkermans, R., Bourbeau, J., Van Weel, C., Vercoulen, J. H., \& Schermer, T. R. J. (2012). Comprehensive self management and routine monitoring in chronic obstructive pulmonary disease patients in general practice: Randomised controlled trial. BMJ (Online), 345(7885), 1-12. https://doi.org/10.1136/bmj.e7642

Borji, M., Otaghi, M., \& Kazembeigi, S. (2017). The impact of Orem's self-care model on the quality of life in patients with type II diabetes. Biomedical and Pharmacology Journal, 10(1), 213-220. https://doi.org/10.13005/bpj/1100

Chang, B., Wu, A. W., Hansel, N. N., \& Diette, G. B. (2004). Quality of life in tuberculosis: A review of the English language literature. Quality of Life Research, 13(10), 1633-1642. https://doi.org/10.1007/s11136-004-0374-1

Deribew, A., Tesfaye, M., Hailmichael, Y., Negussu, N., Daba, S., Wogi, A., Belachew, T., Apers, L., \& Colebunders, R. (2009). Tuberculosis and HIV co-infection: Its impact on quality of life. Health and Quality of Life Outcomes, 7, 1-7. https://doi.org/10.1186/1477-7525-7-105

Diaz, M. A. A., Huff, T. N., \& Libertin, C. R. (2019). Nontuberculous mycobacterial infections of the lower extremities: A 15-year experience. Journal of Clinical Tuberculosis and Other Mycobacterial Diseases, 15, 100091. https://doi.org/10.1016/j.jctube.2019.100091

Donaldson, G. C., Seemungal, T. A. R., Bhowmik, A., \& Wedzicha, J. A. (2008). Relationship between exacerbation frequency and lung function decline in chronic obstructive pulmonary disease (Thorax (2002) 57, (847-852)). Thorax, 63(8), 753. https://doi.org/10.1136/thorax.57.10.847corr1

Estuningsih, Y., Rochmah, T. N., Andriani, M., \& Mahmudiono, T. (2019). Effect of Self-Regulated Learning for Improving Dietary Management and Quality of Life in Patients with Type-2 Diabetes Mellitus at Dr. Ramelan Naval Hospital, Surabaya, Indonesia. Kesmas: National Public Health Journal, 14(2), 51-57. https://doi.org/10.21109/kesmas.v14i2.2257

Fryer, C. E., Luker, J. A., Mcdonnell, M. N., \& Hillier, S. L. (2013). Self-management programs for quality of life in people with stroke. Cochrane Database of Systematic Reviews, 2013(3), 266267. https://doi.org/10.1002/14651858.CD010442

Grady, P. A., \& Gough, L. L. (2018). Self-management: A comprehensive approach to management of chronic conditions. American Journal of Public Health, 108(8), S430-S436. https://doi.org/10.2105/AJPH.2014.302041

Guo, N., Marra, F., \& Marra, C. A. (2009a). Measuring health-related quality of life in tuberculosis: A systematic review. Health and Quality of Life Outcomes, 7, 1-10. https://doi.org/10.1186/14777525-7-14

Guo, N., Marra, F., \& Marra, C. A. (2009b). Measuring health-related quality of life in tuberculosis: A systematic review. Health and Quality of Life Outcomes, 7(March). https://doi.org/10.1186/1477-7525-7-14

Iti, J. L., Mudaraddi, R., Nagaraja, S. B., \& Shastri, S. (2019). Deciphering the Quality of Life among Tuberculosis Patients under RNTCP in Karnataka, India. Journal of Tuberculosis Research, 07(02), 45-55. https://doi.org/10.4236/jtr.2019.72005

Jaber, A. A. S., Khan, A. H., \& Sulaiman, S. A. S. (2019). Evaluating Health-Related Quality of Life of Lost to Follow-Up Tuberculosis Patients in Yemen. World Academy of Science, Engineering and Technology, 13(2), 83-87.

Jaber, A. A. S., Khan, A. H., Sulaiman, S. A. S., Ahmad, N., \& Anaam, M. S. (2016). Evaluation of health-related quality of life among tuberculosis patients in two cities in Yemen. PLoS ONE, 11(6), 1-19. https://doi.org/10.1371/journal.pone.0156258

Jonker, A. A. G. C., Comijs, H. C., Knipscheer, K. C. P. M., \& Deeg, D. J. H. (2009). Promotion of self-management in vulnerable older people: A narrative literature review of outcomes of the Chronic Disease Self-Management Program (CDSMP). European Journal of Ageing, 6(4), $303-$ 314. https://doi.org/10.1007/s10433-009-0131-y

Li, C. T., Chu, K. H., Reiher, B., Kienene, T., \& Chien, L. Y. (2017). Evaluation of health-related quality of life in patients with tuberculosis who completed treatment in Kiribati. Journal of International Medical Research, 45(2), 610-620. https://doi.org/10.1177/0300060517694491

Louw, J. S., Mabaso, M., \& Peltzer, K. (2016). Change in health-related quality of life among pulmonary tuberculosis patients at primary health care settings in South Africa: A prospective cohort study. PLoS ONE, 11(5), 1-13. https://doi.org/10.1371/journal.pone.0151892 
Magharei, M., Jaafari, S., Mansouri, P., Safarpour, A., \& Taghavi, S. A. (2019). Effects of selfmanagement education on self-efficacy and quality of life in patients with ulcerative colitis: A randomized controlled clinical trial. International Journal of Community Based Nursing and Midwifery, 7(1), 32-42. https://doi.org/10.30476/IJCBNM.2019.40844.32

Malik, M., Nasir, R., \& Hussain, A. (2018). Health Related Quality of Life among TB Patients: Question Mark on Performance of TB DOTS in Pakistan. Journal of Tropical Medicine, 2018, 1-7. https://doi.org/10.1155/2018/2538532

Medicine, C. F., Services, A. H., Authority, D. H., Services, A. H., \& Dhabi, A. (2016). and Quality of Life in Diabetes? A Systematic Review of Randomised Controlled Trials. 14(2), 31-43.

Monninkhof, E., van der Valk, P., van der Palen, J., van Herwaarden, C., \& Zielhuis, G. (2003). Effects of a comprehensive self-management programme in patients with chronic obstructive pulmonary disease. European Respiratory Journal, 22(5), 815-820. https://doi.org/10.1183/09031936.03.00047003

Mousa, I., Ataba, R., Al-ali, K., Alkaiyat, A., \& Zyoud, S. H. (2018). Dialysis-related factors affecting self-efficacy and quality of life in patients on haemodialysis: a cross-sectional study from Palestine. Renal Replacement Therapy, 4(1), 1-12. https://doi.org/10.1186/s41100-018-0162-y

Muhammad, A., Syed Sulaiman, S., Shafie, A., Muhammad, A., Muhammad, S., Heng, L., \& ZaheerUd-Din, B. (2014). Impacto del tratamiento de la tuberculosis en la calidad de vida relacionada con la salud de los pacientes con tuberculosis pulmonar: un estudio de seguimiento. Health and Quality of Life Outcomes, 12(1), 19. https://doi.org/10.1186/1477-7525-12-19

Nahid, P., Mase, S. R., Migliori, G. B., Sotgiu, G., Bothamley, G. H., Brozek, J. L., Cattamanchi, A., Peter Cegielski, J., Chen, L., Daley, C. L., Dalton, T. L., Duarte, R., Fregonese, F., Robert Horsburgh, C., Khan, F. A., Kheir, F., Lan, Z., Lardizabal, A., Lauzardo, M., ... Wortham, J. M. (2019). Treatment of drug-resistant tuberculosis an official ATS/CDC/ERS/IDSA clinical practice guideline. In American Journal of Respiratory and Critical Care Medicine (Vol. 200, Issue 10). https://doi.org/10.1164/rccm.201909-1874ST

Navicharern, R. (2012). Diabetes self-management, fasting blood sugar and quality of life among type 2 diabetic patients with foot ulcers. Journal of the Medical Association of Thailand, 95(2), 156162.

Of, E., In, A. W., Self-efficacy, E. O. N., Of, Q., Of, L., With, P., \& Disease, C. H. (2019). $B$ ELITUNG N URSING EDUCATION ON SELF-EFFICACY AND EFFECT OF A WORKBOOK IN HEALTH EDUCATION ON SELF-. 5(6).

Salehitali, S., Noorian, K., Hafizi, M., \& Dehkordi, A. H. (2019). Quality of life and its effective factors in tuberculosis patients receiving directly observed treatment short-course (DOTS). Journal of Clinical Tuberculosis and Other Mycobacterial Diseases, 15, 100093. https://doi.org/10.1016/j.jctube.2019.100093

Sangprasert, P., Palangrit, S., Tiyoa, N., \& Pattaraarchachai, J. (2019). Effects of mindfulness-based health education practice on health behaviors and quality of life among hypertensive patients: A quasi-experimental research. Journal of Health Research, 33(3), 186-196. https://doi.org/10.1108/JHR-07-2018-0059

Shahhamzeh, M., T, F. H., Kabir, K., Montazeri, A., M, A. S., \& Saei, V. (2017). The Relationship between Self-Management and Quality of Life in Epileptic Patients who referred to Iranian Epilepsy Association. 19(2), 189-198.

Sharma, N., Sharma, P., Sharma, N., \& Wavare, R. R. (2013). A cross sectional study of knowledge , attitude and practices of menstrual hygiene among medical students in north India. The Journal of Phytopharmacology, 2(5), 28-37.

Sule, A., Odeigah, L., Alabi, K., Issa, B., Shittu, R., Joseph, A., Abiola, O., \& Natie, B. (2014). Quality of Life of Patients with Tuberculosis in a Nigerian Teaching Hospital. Turkish Journal of Family Medicine \& Primary Care, 8(2), 39. https://doi.org/10.5455/tjfmpc.46982

Sun, Y., Yang, Z., Wan, C., Xu, C., Chen, L., Xu, L., Zhang, X., \& Yan, F. (2018). Development and validation of the pulmonary tuberculosis scale of the system of Quality of Life Instruments for Chronic Diseases (QLICD-PT). Health and Quality of Life Outcomes, 16(1), 1-10. https://doi.org/10.1186/s12955-018-0960-5

Tung, H. H., Lin, C. Y., Chen, K. Y., Chang, C. J., Lin, Y. P., \& Chou, C. H. (2013). Selfmanagement intervention to improve self-care and quality of life in heart failure patients. 
Congestive Heart Failure, 19(4), 9-16. https://doi.org/10.1111/chf.12014

Voncken-Brewster, V., Moser, A., Van Der Weijden, T., Nagykaldi, Z., De Vries, H., \& Tange, H. (2013). Usability evaluation of an online, tailored self-management intervention for chronic obstructive pulmonary disease patients incorporating behavior change techniques. Journal of Medical Internet Research, 15(1), 1-11. https://doi.org/10.2196/resprot.2246

Xu, S., Zhang, Z., Wang, A., Zhu, J., Tang, H., \& Zhu, X. (2018). Effect of Self-efficacy Intervention on Quality of Life of Patients with Intestinal Stoma. Gastroenterology Nursing, 41(4), 341-346. https://doi.org/10.1097/SGA.0000000000000290

Yu, S. H., Guo, A. M., \& Zhang, X. J. (2014). Effects of self-management education on quality of life of patients with chronic obstructive pulmonary disease. International Journal of Nursing Sciences, 1(1), 53-57. https://doi.org/10.1016/j.ijnss.2014.02.014 